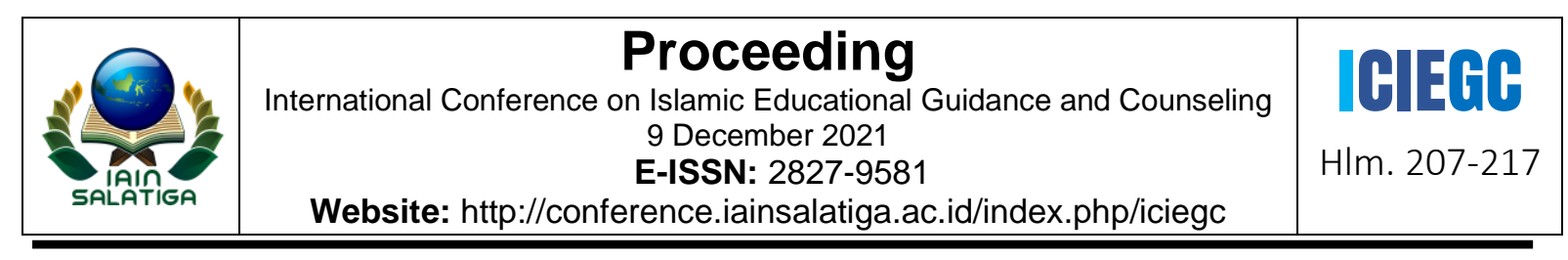

\title{
PELAYANAN KONSELING RELIGIUS KYAI KAMPUNG PADA MASYARAKAT MODERN
}

Muhamad Rozikan

Institut Agama Islam Negeri Salatiga

\begin{tabular}{ll}
\hline \hline Informasi Artikel & ABSTRACT \\
\cline { 2 - 3 } $\begin{array}{l}\text { Penulis Korespondensi: } \\
\text { Email: muhamadrozikan }\end{array}$ & The purpose of this research is to find out how the competence and \\
@iainsalatiga.ac.id & model of religious counseling service of village kyai in modern \\
& society. This type of research is descriptive qualitative research. \\
& Sources of data in this study include primary data and secondary \\
& data. Methods of data collection is done by observation, interviews, \\
& and documentation. The validity of the data was obtained through \\
& triangulation. Furthermore, the collected data were analyzed by \\
& means of data reduction, data presentation, and drawing \\
& conclusions. The results of the study show that the competence of \\
& the village kyai spiritual counselor is as follows: (a) understanding \\
& the nature of humans as God's creatures (b) convincing the \\
& counselee that God is the helper of humans (c) guiding the \\
& counselee's religious life during the counseling process (d) being an \\
& inspiration for the counselee during the counseling process. \\
& counseling process (e) developing oneself as a facilitator to provide \\
& counseling services, (f) applying the professional characteristics of \\
& general counselors (having good psychological health, self- \\
& awareness, open mind, empathy, unconditional view of positive \\
& things, genuineness) and conformity (congruence), and non- \\
& judgment (g) using religious resources in the counseling process (h) \\
applying religious coping to help counselees. Three counseling \\
techniques are used by the village kyai: First, counseling by hand \\
(power), with authority. The counselor interprets the hand for \\
therapy, Second, oral counseling, by giving advice, discussing, \\
interviewing the counselee, Third, prayer techniques.
\end{tabular}

\begin{tabular}{l}
\hline Keyword: Religious counseling; kyai kampung; community \\
\hline ABSTRAK \\
\hline Tujuan penelian ini adalah untuk mengetahui bagaimana kompetensi \\
dan model pelayanan Konseling religius kyai kampung pada \\
masyarakat modern. Jenis penelitian ini adalah penelitian deskriptif \\
kualitatif. Sumber data dalam penelitian ini meliputi data primer dan \\
data sekunder. Metode pengumpulan data dilakukan dengan \\
observasi, wawancara, dan dokumentasi. Keabsahan data diperoleh \\
melalui trianggulasi. Selanjutnya data yang terkumpul dianalisis \\
dengan cara reduksi data, penyajian data, dan penarikan kesimpulan. \\
Hasil penelitian menunjukkan Kompetensi konselor spiritual kyai \\
kampung sebagai berikut: (a) memahami hakikat manusia sebagai \\
makhluk ciptaan Tuhan (b) meyakinkan kepada konseli bahwa Tuhan \\
sebagai penolong manusia (c) membimbing kehidupan religius \\
konseli selama proses Konseling (d) menjadi inspiraitor bagi konseli \\
selama proses konseling (e) mengembangkan diri sebagai fasilitator \\
untuk memberikan layanan Konseling, (f) menerapkan karakteristik
\end{tabular}


profesional konselor umum (memiliki kesehatan psikologis yang baik, mempunyai kesadaran diri, pikiran terbuka, berempati, pandangan tak bersyarat terhadap hal positif, bersifat asli (genuineness) dan kesesuaian (congruence), serta tidak menghakimi) (g) menggunakan sumber daya religius dalam proses Konseling (h) menerapkan coping religius untuk membantu konseli. Tiga teknik konseling yang dilakukan oleh kyai kampung: Pertama, konseling dengan tangan (kekuasaan), otoritas. Konselor memaknai tangan untuk terapi, Kedua, konseling dengan lisan, dengan memberi nasehat, berdiskusi, wawancara dengan konseli, Ketiga, teknik doa.

Kata kunci: Konseling religius; kyai kampung; masyarakat

\section{PENDAHULUAN}

Secara umum, masyarakat yang berada di perkotaan memiliki sifat egois, individual, dan materialistis dengan penuh kehidupan glamor yang dikelilingi berbagai macam gedunggedung yang menjulang tinggi, pabrik dan perkantoran, sehingga banyak orang mengasumsikan bahwa kota merupakan tempat yang dapat merubah nasib dalam menggapai kesuksesan. Di lingkungan perkotaan terbuka lebar lapangan kerja yang mengakomodir kelompok buruh, pekerja, pegawai, dan pekerjaan disektor informal (PKL), pemulung, pengemis, tukang sapu jalanan, tukang becak, dan lain sebagainya. Dalam kehidupan sosiologis pola yang dibangun dalam masyarakat bisnis, wiraswasta, dan industri, dan lainnya (Jamaludin, 2015) Secara fisik dalam lingkungan perkotaan terdapat kemacetan lalu lintas, kesibukan warga, dan persaingan cukup tinggi dan lain sebagainya.

Masyarakat yang berada dalam perkotaan (Mahdi, 2012) merupakan masyarakat yang lingkungannya memiliki orientasi peradaban dan budaya masa kini. Berbeda dengan masyarakat yang berada di lingkungan desa. Kehidupan di lingkungan modern dapat dikatakan sebagai bentuk eksploitasi kepada individu masing-masing. Kehidupan modern (Nilyati, 2015) lebih condong terkena penyakit stress dan penyakit lainnya yang membuat pribadinya samakin terpuruk akibat pola pikir, kerja dan makan.

Masyarakat di lingkungan industry modern (Kartono \& Nurcholis, 2016) dapat dikhaskan sebagai masyarakat yang lebih maju. beberapa karakteristik yang dialami oleh masyarakat perkotaan, yakni pertama, kehidupan yang berkaitan dengan keagamaan sangat berkurang, dan terkadang jauh apa yang dipikirkan karena kehidupan yang digelutinya cenderung pada ranah keduniaan, kedua, masyarakat di lingkungan perkotaan umumnya mampu mengatasi permsalahannya sendiri dan dapat dikatakan sebagai masyarakat yang mandiri. ketiga, Kemungkinan mendapatkan usaha dan pekerjaan juga lebih baik bila dibandingkan dengan masyarakat yang berada di desa. Keempat, Sektor perubahan semakin nyata di belahan kota, sebab lingkungan perkotaan akan terbuka oleh berbagai pengaruh 
dari luar, kelima, perkotaan tidak akan memperdulikan terhadap sesama dan cenderung mempunyai aktivitas masing-masing. Kontrol sosial yang terjadi di lingkungan masyarakat perkotaan dapat simpulkan sangat lemah, keenam, secara fisik, anggota masyarakat perkotaan hidup saling berdekatan akan tetapi jauh secara sosial. dan ketujuh, perbedaan yang siginifikan tingkat status sosial, dan Pendidikan.

Masyarakat perkotaan selalu identik dengan masyarakat rasionalis, yaitu masyarakat yang memiliki pola pikir idealis dan kritis. Tidak sedikit permasalahan yang dihadapi oleh masyarakat perkotaan bahkan sangat komprehensif, dan kompleks, diantara permasalahan yang dihadapi adalah persoalan karir, ekonomi, belajar, pribadi dan sosial, keluarga keberagamaan dan lain sebagainya.

Permasalahan-permasalahan yang dihadapi masyarakat perkotaan tentunya berdampak pada pengembangan diri seseorang, pencarian solusi untuk keluar dari masalah terus dilakukan dan diupayakan, sebagai masyarakat perkotaan kemampuan berpikir logis tentunya digunakan untuk mencari jalan keluar agar permasalahannya segera teratasi, di antara pencarian untuk menemukan penyelesaian masalah adalah mencari konselor untuk melakukan aktivitas konseling.

Konseling merupakan pelayanan bantuan yang dilakukan oleh konselor secara face to face yang sifat penuh rahasia, penuh dengan sikap accepted dan pemberian kesempatan pada klien atau konseli, kemudian konselor juga menerapkan skill dan keterampilannnya dalam membantu konselinya dalam mengentaskan masalahnya.(Cavalet \& Knechtel, 2019; Neuer Colburn, 2017).

Lembaga-lembaga konseling yang ada di masyarakat atau lembaga konseling yang ada di perguruan tinggi yang tersertifikasi tentunya akan menjadi pilihan yang tepat bagi masyarakat perkotaan untuk melakukan konseling terhadap permasalahan yang dihadapinya.

Namun fakta di lembaga konseling yang ada di perguruan tinggi tidak banyak diminati oleh masyarakat perkotaan untuk melakukan konseling di lembaga tersebut. Lalu kemanakah masyarakat perkotaan melakukan konseling? ini menjadi sebuah pertanyaan yang harus ditelusuri. Hasil wawancara peneliti dengan seorang kyai yang berdomisili di Kabupaten Semarang menemukan fakta bahwa banyaknya masyarakat perkotaan melakukan konseling terhadap kyai untuk mengentaskan permasalahan-permasalahan yang dihadapinya. 
Eksistensi kyai kampung lebih mendapatkan kepercayaan publik bagi masyarakat perkotaan untuk melakukan konseling dibanding dengan lembaga-lembaga konseling formal yang tersertifikasi. Hal ini membuktikan kompetensi konseling komprehensif yang dimiliki kyai kampung mendapat kepercayaan yang cukup bagi masyarakat.

Hal inilah yang menarik untuk diteliti lebih detail lagi mengenai kompetensi ini, mengingat selama ini masyarakat perkotaan lebih tertarik melakukan konseling pada kyai yang notabene tidak pernah mengikuti pendidikan konseling di lembaga formal seperti perguruan tinggi. Keunikan kompetensi ini dapat menggiring keinginan peneliti untuk menjadikan kyai kampung sebagai role model dalam pengembangan kompetensi konseling di masyarakat terlebih menyiapkan konselor-konselor Muslim di kampus-kampus Islam.

\section{METODE}

Jenis penelitian ini adalah penelitian deskriptif kualitatif. Sumber data dalam penelitian ini meliputi data primer dan data sekunder. Metode pengumpulan data dilakukan dengan observasi, wawancara, dokumentasi pada kyai, masyarakat di kabupaten Kudus. Keabsahan data diperoleh melalui trianggulasi. Selanjutnya data yang terkumpul dianalisis dengan cara reduksi data, penyajian data, dan penarikan kesimpulan.

\section{HASIL DAN BAHASAN}

\section{Masyarakat Perkotaan}

Kehidupan di lingkungan masyarakat modern seperti telah dikatakan oleh $\mathrm{Ch}$. H. Cooley (Blikharskyi, 2020) dengan teori mutakhirnya mengenai bayangan sebuah kaca. Setiap individu yang mengaca mengukur dirinya sendiri dan kepribadiannya akan tampak dan terbayang pada dirinya sendiri. Beberapa faktor yang dapat mempengaruhi persoalanm tersebut: (a) faktor kebutuhan, (b) faktor perkembangan, dan (c) faktor ekonomi

Dalam konteks sosiologi ilmu yang menyelidiki kehidupan individu dalam sebuah lingkungan masyarakat akan memiliki arah yang sama, ilmu yang telah dipelajari terkait dengan kontak manusia dan golongannya atau dapat berinteraksi individu bersama kelompok. Kewajiban individu mengadakan hubungan kebutuhan satu dengan yang lainnya. Anggota masyarakat modern akan melaksanakan aktivitas-aktivitas selama 24 jam di lingkungan keluarga dan masyarakat. Individu perkotaan menjalankan aktivitas kerja tanpa batas ruang dan waktu. Individu dapat berdagang dengan msayarakat duni, seperti kegiatan eksport dan import, serta melakukan perdagangan toko termasyhur. Tak hanya di bidang bisnis dan ekonimi, akan tetapi kegiatan di bidang sosial budaya dan pendidikan, 
pariwisata dan lain sebagainya, di bidang sosial akan tampak siginifikan pola perbedaan yang berada dalam lingkungan perkotaan dan pedesaan.

\section{Konseling Religius}

Fauzi dan Hasby (Fauzi et al., 2020; Habsy, 2017) mengatakan bahwa Konseling adalah hubungan yang saling membantu orang lain, untuk mengentaskan masalahnya, dan mampun menjadi pribadi yang mandiri dalam mengembangkjan dirinya kearah yang lebih baik, dan mampu menyelesaikan tugas perkembangannya.

Carl Rogers, (Thorne \& Sanders, 2013), berpendapat bahwa pelayaan konseling merupakan aktivitas pemberian terapi kepada konseli yang mempunyai maksud untuk perubahan diri pada konseli.

Tugas seorang konselor selalu dapat menciptakan kondisi konseli dalam upaya untuk pengembangan dan pertumbuhannya. Hubungan dalam proses konseling bersifat interpersonal. Di sana akan terbentuk sebuah wawancara antara ko nselor dan konseli. Dan melibatkan unsur kepribadian yang meliputi pengalaman, perasaan nilai-nilai, kebutuhan dan harapan.

Tujuan konseling adalah untuk melakukan perubahaan tingkah laku konseli menuju kearah yang lebih memuaskan dan produktif dalam membntuk self-actualization dan mampu mengembangkan potensi yang ada dalam hidupnya.

Spiritual (spirituality) (Ayranci \& Semercioz, 2011) dapat diartikan sebagai kekuatan yang menghidupkan, dipresentasikan melalu citra, kekuatan, keberanian, nafas dan angin. bebarapa pengertian spiritualitas, yaitu sebagai berikut : (1) ekpresi aktivitas spirit individu, (2) proses dalam individu dan sosial merujuk pada konsep, sikap, dan perilaku (3) kesadaran transendental dengan nilai-nilai tertentu, baik diri, dan alam sekitar, (4) pengalaman tentang intra dan inter-transpersonal yang dinamis, (5) aktivitas indivudu yang mencoba untuk mengekpresikan pengalaman yang mendalam dan bermakna, (6) kecenderungan dan kapasitas yang bersifat khas, (7) kecerdasan yang bersifat ketuhanan dalam membangun keharmonisan dengan Allah swt.

Konseling religius (Hasan, 2020; Saprudin, 2019) dapat dijelaskan "proses bantuan yang diberikan kepada manusia agar dapat meningkatkan kemampuan dalam mengembangkan dirinya sebagai makhluk beragama (homo religius), bertingkah laku berdasar atas nilai-nilai agama. 


\section{Kompetensi Konseling Kyai Kampung}

Kompetensi utama kyai kampung dalam pendekatan konseling adalah kompetensi religius (agama). Kompetensi spiritual diartikan seperangkat kemampuan yang dimiliki konselor dalam memahami agama secara komprehensif baik dari aspek pengetahuan maupun perilakunya. Kompetensi konselor spiritual kyai kampung sebagai berikut: (a) memahami hakikat manusia sebagai makhluk ciptaan Tuhan (b) meyakinkan kepada konseli bahwa Tuhan sebagai penolong manusia (c) membimbing kehidupan religius konseli selama proses Konseling (d) menjadi inspiraitor bagi konseli selama proses konseling (e) mengembangkan diri sebagai fasilitator untuk memberikan layanan Konseling, (f) menerapkan karakteristik profesional konselor umum (memiliki kesehatan psikologis yang baik, mempunyai kesadaran diri, pikiran terbuka, berempati, pandangan tak bersyarat terhadap hal positif, bersifat asli (genuineness) dan kesesuaian (congruence), serta tidak menghakimi) (g) menggunakan sumber daya religius dalam proses Konseling (h) menerapkan coping religius untuk membantu konseli.

\section{Peran Kyai Kampung sebagai Helper}

Sementara itu peran konselor religius dapat dijelaskan sebagai seperangkat perilaku yang diharapkan ada pada konselor religius. Peran sentral konselor religius adalah sebagai penasihat religius, dengan kebutuhan konseli akan metafisik (keyakinan kepada Tuhan) dan emosional. Dalam konteks ini, peran konselor religius haruslah individu yang mempunyai kepercayaan diri untuk membantu dan mengembangkan orang lain dalam religius.

Konselor religius dapat menjadi penasihat religius dari berbagai macam pengalaman keagamaan serta memahami ragam perbedaan agama. Akan tetapi apabila peran tersebut sulit dicapai, maka syarat minimal untuk peran konselor religius sebagai penasihat religius adalah memahami dengan baik agama yang dianutnya maupun agama yang dipeluk konseli.

Disamping berperan sebagai penasihat religius, konselor religius juga memiliki peran yang menggambarkan kehadiranya dalam setting konseling secara keseluruhan, baik pada saat proses konseling maupun di luar konseling. Adapun peran konselor religius adalah sebagai berikut: (1) teladan bagi konseli, dan (2) pembimbing bagi konseli untuk penguatan keyakinan kepada Tuhan.

Peran kyai sebagai pembimbing untuk membantu masyarakat perkotaan memahami hakikat kehidupan religius, dan sebagai imam dan modeling bagi konseli. Disamping itu, 
konselor spiritual mempunyai peran sebagai pelayan konseli untuk menemukan kebahagiaan dengan cara membatu kesadaran diri (self) konseli kearah yang lebih baik.

\section{Pelayanan Konseling Kyai Kampung}

Landasan konseling Islam adalah nilai-nilai yang digali dari ajaran Islam. Al-Qur'an adalah sumber bimbingan, nasihat dan obat untuk menanggulangi permasalahan. Qs.Yunus, 57 menyatakan "Hai manusia, Sesungguhnya telah datang kepadamu pelajaran dari Tuhanmu dan penyembuh bagi penyakit (yang berada) dalam dada dan petunjuk serta rahmat bagi orang-orang yang beriman". Para Rasul, Nabi dan Auliya-Nya menjadi contoh konselor dan terapis utusan Allah SWT. 'Dialah Allah yang telah mengutus ditengah-tengah orang-orang yang kurang wawasan seorang Rasul dari kalangan mereka, ia akan membacakan ayat-ayat-Nya kepada mereka dan mensucikan mereka serta mengajarkan kepada mereka Al hikmah. Dan sesungguhnya mereka sebelumnya benar-benar dalam kesesatan yang nyata". Landasan konseling Islam merujuk QS an Nahl 125: "Serulah (manusia) kepada jalan Tuhan-mu dengan hikmah dan pelajaran yang baik dan bantahlah mereka dengan cara yang baik. Sesungguhnya Tuhanmu Dialah yang lebih mengetahui tentang siapa yang tersesat dari jalan-Nya dan Dialah yang lebih mengetahui orang-orang yang mendapat petunjuk". (QS Al-Jum'ah : 2). Dari ayat di atas, konseling Islam harus hikmah. Hikmah mengandung makna mengetahui keunggulan sesuatu melalui suatu pengetahuan, sempurna, bijaksana dan suatu yang tergantung pada akibat sesuatu yang terpuji; Hikmah bermakna ucapan yang sesuai dengan kebenaran, falsafah, perkara yang benar dan lurus, keadilan, pengetahuan, dan lapang dada; Hikmah yang dalam bentuk jamaknya al Hikam bermakna kebijaksanaan, ilmu dengan pengetahuan, filsafat, kenabian, keadilan, pepatah, dan al Qur'an.

Konseling spiritual kyai kampung berupaya membantu individu belajar untuk mengembangkan fitrah-iman, dengan memberdayakan fitrah-fitrah (rohani, jasmani, nafs, dan iman) mempelajari dan melaksanakan tuntunan Allah dan rasul-Nya, agar fitrah-fitrah yang ada pada individu berkembang dan berfungsi dengan baik dan benar, dan akhirnya memperoleh kebahagiaan sejati di dunia dan akhirat. Konseling spiritual kyai kampung mendekatkan manusia pada fitrahnya yang positif dan membantu mereka agar tidak salah jalan dalam memenuhi dorongan nafsunya sehingga dorongan itu tersalur secara benar, bahkan sebaliknya, mendorong manusia mencapai kemajuan yang positif. Dengan demikian, pendekatan konseling Islam untuk menselaraskan kembali kepribadian manusia 
sesuai tuntunan Islam, penemuan makna hidup, penyembuhan gangguan emosional, penyesuaian terhadap masyarakat, pencapaian kebahagiaan dan kepuasan, pencapaian aktualisasi diri, peredaan kecemasan serta penghapusan tingkah laku mal-adaptif dan belajar tingkah laku adaptif sebagaimana yang diajarkan Islam.

\section{Teknik Konseling Religius}

Teknik dan praktik konseling religius berupa aktivitas menolong sesama muslim yang mengalami permasalahan hidup. Dalam ajaran Islam, praktek ini memiliki dasar kuat sebagaimana ayatayat tentang saling membantu dalam kebaikan dan kesabaran menghadapi masalah, membantu orang lain dengan ikhas, membantu dengan hikmah, saling mendorong untuk berbuat dalam kebaikan (tawaa shaubil-haqq,tawaa shaubisshabr; wallahu fii 'auni 'abdi maa kaanal 'abdu fii 'auni akhiihi; ud'u ilaa sabiili rabbika bilhikmati, wal mau'idzatil hasanati wa jaadilhum billatii hiya ahsan..; ta'aawanuu 'alal birri wat taqwa walaa ta'aawanuu 'alal itsmi wal 'udwan). Rasulullah sebagai konselor didasari al-Qur'an dan al-Hadits. Hadits Nabi: "man nafasa kurbatan min kurabiddunya naffasahullahu kurbatan min kurabil akhirah" (al-Hadits). Tindakan menolong dan meringankan beban orang lain termasuk amaliyah shalih yang sangat dihargai Allah. Amaliah ihsan sangat dicintai oleh Allah swt. Konseling yang dilakukan Rasul dan para sahabat mencakup perubahan sikap, pemahaman, dan perilaku yang islami. Konseling spiritual berorientasi pada penguatan nilai-nilai moral dan nilai ibadah. Nilai moral seperti kejujuran, amanah, kesetiaan, keadilan, komitmen, kasih sayang, kebersamaan, kesabaran, keharmonisan, sedangkan fokus orientasi penguatan nilai ibadah Islam seperti kekhusu'an dalam ibadah, keikhlasan, keistiqamahan. Praktik konseling telah hadir juga bentuk cara dakwah Rasulullah dalam menyelesaikan problem-problem yang dihadapi oleh para sahabat, melalui interaksi yang berlangsung antara Rasul (konselor) dengan umat (konseli), baik secara kelompok (misalnya pada model halaqah ad-dars) maupun secara individual. Konseling Islam menyatu dengan dakwah. Mendasarkan pada hadis Nabi, 'Barang siapa melihat kemungkaran, maka dianjurkan untuk merubahnya dengan tangannya, bila tidak mampu, dengan lisannya, bila tidak mampu, dengan hatinya. Maka siapa yang melakukan perubahan dengan hati, ia merupakan tindakan selemah-lemahnya iman (HR. Muslim dari Abu Said al Khuduri ra.). Teknik konseling didasarkan pada prinsip kerahasiaan, kepercayaan, rasa hormat, cinta, mendengarkan dengan empati, pengertian. Tujuannya memberikan solusi spiritual kepada mereka menggunakan cara meningkatkan komunikasi dengan Allah. Konseling Islam menekankan solusi spiritual, berdasarkan cinta dan takwa 
kepada Allah, kewajiban untuk memenuhi tanggung jawab manusia sebagai hamba Allah di muka bumi.

Konseling religius menjadi solusi bagi masyarakat Muslim, karena mereka meyakini bahwa Islam adalah cara hidup yang memandu manusia ke jalan yang benar, Islam mengajarkan bagaimana mengatasi masalah. Konseling Islam bersifat preventif, kuratif, rehabilitative dan development. Praktek-praktek konseling dapat menggunakan instrumen dan teknik konseling yang dikembangkan para ahli, diselaraskan dengan nilai-nilai Islam.

Tiga teknik konseling religius yang dilakukan oleh kyai kampung: Pertama, konseling dengan tangan (kekuasaan), otoritas. Konselor memaknai tangan untuk terapi. Misalnya dengan memijat-mijat bagian leher dan pundak klien, sehingga terjadi rileksasi. Ketika klien mengalami rikes, konselor memberikan nasihat-nasihat berdasar dari data yang telah diperolehnya dari ungkapan yang dikeluhkan klien. Muslim meriwayatkan, dari Utsman bin Abil 'Ash ra, bahwasannya ia pernah mengadukan penderitaannya kepada Rasulullah karena ia telah menemukan suatu penyakit di tubuhnya sejak ia masuk Islam. Lalu Rasulullah bersabda: "letakkanlah tangan mu pada tubuh mu yang merasa sakit, lalu ucapkanlah Bismillah sebanyak tiga kali dan ucapkanlah dengan kalimat aku berlindung kepada Allah dari kejahatan yang aku temui dan yang aku waspadai”. Konselor dapat juga memberikan sedikit penekanan dengan otoritasnya ketika melakukan konseling agar klien yakin atas kemampuan konselor. Kedua, konseling dengan lisan, dengan memberi nasehat, berdiskusi, wawancara dengan konseli. Dengan berdiskusi dan nasehat al Qur'an, sirah para nabi dan rasul, kisah para auliya' dan sholihin dapat menginsiprasi. Ketiga, teknik doa. Sering ketika kita sowan ke kiai sepuh bukan nasehat yang dibutuhkan, tetapi doa dari kiai sepuh itulah yang dibutuhkan. Teknik konseling spiritual juga menggunakan amalan yang sesuai al-Quran dan Sunnah seperti wudlu, dhikir dan sholat. Teknik konseling tersebut digunakan sejak dulu untuk menyelesaiakan banyak masalah termasuk kesehatan mental. Teknik konseling spiritual dapat menerapkan metode spiritual (spiritualism methode) dan metode berpusat anak (client-centered method). Metode spiritual terdiri dari teknik latihan spiritual, menjalin kasih sayang, dan cerminan al-qudwah al-hasanah.

Metode religius, konseli diarahkan untuk mencari ketenangan hati dengan mendekatkan diri kepada Alloh sebagai sumber ketenangan hati, sumber kekuatan penyelesaian masalah dan sumber penyembuhan penyakit mental. Diawali dengan menyadarkan konseli agar menerima masalah dengan lapang dada dan tawakal atas dasar keteguhan iman. Selanjutnya menegakkan potensi tauhidnya secara benar agar yakin bahwa 
Allah satu-satunya tempat mengembalikan masalah dan memohon pertolongan penyelesaiannya. Metode ini dilanjutkan dengan menuntun kearah mendekati Alloh melalui amal ibadah yang dilaksanakan dengan khusu' hingga pada gilirannya mereka dapat memiliki hati sehat dan jiwa tenteram, seperangkat sifat-sifat terpuji serta dapat mencapai kehidupan bahagia (pendekatan non direktif), konseli dipandang memiliki hak memilih, merencanakan, memutuskan tentang perilaku dan nilai-nilai yang paling bermakna baginya. Konseli diberi kesempatan untuk mengekspresikan segala gangguan psikis yang menjadi problem, kemudian konselor menganalisis fakta-fakta psikis untuk mengusahakan kesembuhannya. Selanjutnya konseli didorong untuk berusaha sendiri memahami masalahnya, menemukan keadaan baru dan memilih alternatif tindakan penyelesaian masalah. Konselor membantu menyediakan kondisi-kondisi yang memberikan kemudahan baginya untuk mengembangkan perilaku secara lebih produktif, sehingga konseli lebih mandiri dalam menyelesaikan masalahnya.

\section{KESIMPULAN}

Pelayanan konseling religius yang dilakukan oleh kyai kampung kepada masyarakat umum menjadi sebuah model tersendiri dan cara unik yang dilakukan dalam upaya sebagai seorang helper. Banyaknya masyarakat yang tertegun dan melakukan konsultasi berbagai persoalan selalu melibatkan kyai kampung yang sudah memiliki public trust untuk membantu klien dalam memecahkan permasalahan yang dihadapinya. Peran kyai kampung dalam melayani Konseling, Kompetensinya dan berbagai Teknik pelayanan Konseling yang dilakukan oleh kyai kampung menjadi salah satu kekhasan yang dimiliki oleh kyai kampung yang notabene kyai yang berada di pedesaan tetapi memiliki peran yang cukup dipercaya oleh masyarakat dalam membantu problem ummat yang komprehensif.

\section{DAFTAR RUJUKAN}

Ayranci, E., \& Semercioz, F. (2011). The Reelationship between Spirituaal Leadership and Issues of Spirituality and Religiosity: A Study of Top Turkish Managers. International Journal of Business and Management. https://doi.org/10.5539/ijbm.v6n4p136

Blikharskyi, R. (2020). «The truth and her shadow»: anti-modern rhetoric on the pages of the Galician religious journals of the second half of the XIX - early XX century. Proceedings of Research and Scientific Institute for Periodicals. https://doi.org/10.37222/2524-0331-2020-10(28)-6

Cavalet, J., \& Knechtel, M. (2019). Patint Educaaion and Counseling. In The Physician Assstant Student's Guide to the Clinical Year: Behavioral Health. https://doi.org/10.1891/9780826195388.0004

Fauzi, Z., Heiriyah, A., \& Matarif, J. (2020). Upaya Pelayannan Guru Bmbingan Dan 
Konseling Selama Pandeemi Covid-19 Pada Siswa Di Smp Negeri 23 Banjarmasin. Urnal Mahasiswa BK An-Nur.

Habsy, B. A. (2017). Filosfi Ilmu Bimbingan Dan Konseling Indonesia. Jurnal Pendidikan (Teori Dan Praktk). https://doi.org/10.26740/jp.v2n1.p1-11

Hasan, I. (2020). Konseling Spiritual pada Penderita Gangguan Mental di Pondok Pesantren Rehabilitas Salafiyah Syafi'iyah Nasrun Minallah Ygyakarta. Jurnal Mimbar: Media Intelektual Muslim Dan Bimbingan Rohi. https://doi.org/10.47435/mimbar.v6i1.160

Hidayat, A. (2017). Penjelasan Teknik Purposive Sampling Lngkap Detail - Uji Statistik. In Statistikian.

Jamaludin, A. N. (2015). Sosologi Perkotaan. Sosiologi Perkotaan.

Kartono, D. T., \& Nrcholis, H. (2016). Pembangunan Masyarakat Desa dab Kota. Pembangunan Masyarakat Desa Dan Kota.

Lexi J.Moloeng. (2010). Metdologi Penelitian Kualitatif. In Mtodologi Penelitian Kualitatif. Rake Sarasin.

Lubis, S. A. (2011). Islamic conseling: The services of mental health and edcation for people. Religious Education. https://doi.org/10.1080/00344087.2011.613347

Mahdi. (2012). Urgnsi Akhlak Tasawuf Dalam Khidupan Masyarakat Modern. Jurnal Edueksos.

Neur Colburn, A. A. (2017). Creer counseling. In Introdction to the Counseling Profession: Seventh Edition. https://doi.org/10.4324/9781315537061

Nilyati, N. (2015). PERANAN TASAWUF DALAM KEHIDUPAN MODERN. TAJDID: Jurnal Ilmu Ushuluddin. https://doi.org/10.30631/tjd.v14i1.24

Permana, E. J. (2015). Pelaksanan Laynan Bimbingan dan Konseling di Madrasah Aliyah Negeri 2 Banjarnegara. PSIKOPEDAGOGIA Jurnl Bimbingan Dan Konseling. https://doi.org/10.12928/psikopedagogia.v4i2.4493

Saprudin, U. (2019). KONSEP BIMBINGAN DAN KNSELING SPIRITUAL: KERANGKA KERJA UNTUK GURU BIMBINGAN DAN KONSELING. Jurnal Penelitian Bimbingan Dan Konseling. https://doi.org/10.30870/jpbk.v4i1.5233

Suwendra, I. W. (2018). Metodologi Penelitian Kualitatif dalam Ilmu Sosial, Pendidikan, Kebudayaan, dan Keagamaan. In NilaCakra Publishing House, Bandung.

Thorne, B., \& Snders, (2013). Carl rogers. In Carl Rogers. https://doi.org/10.4135/9781446289051 